\title{
PENGEMBANGAN TABLET EFERVESEN KOMBINASI BROKOLI DAN PEGAGAN DENGAN KOMBINASI ASAM DAN BASA
}

\author{
Yuliana Kusumawati, Erni Rustiani, Almasyuhuri \\ Program Studi Farmasi, FMIPA, Universitas Pakuan Bogor \\ yulianakusumawatii@gmail.com
}

\begin{abstract}
Brocoli and pegagan is a plant that is easy to get and efficacious as antidemensia. The objective of this study was to formulate the plant into an effervescent tablet preparation and to determine the best formula with acid concentration variation. Dry extract of brocoli and pegagan is made by the method of escape then dried with vacuum dryer. The preparation is made by wet granulation method of 3 formula with weight of 4 gram per tablet. The granule test includes moisture content. Result of granule water content $<5 \%$. Granules are printed in special chambers and conditions and tested for quality. The result of uniform weight test of all formula meets the requirements of Pharmacopoeia Indonesia III; Hardness of tablets 12.06-12.52 kP; Friability of tablets 0.083-0.74\%; Test of dissolution time of efervesen tablet $<5$ minutes. Preferred test results showed formula III with citric acid concentration: 1: 2 tartaric acid most preferred. ; Test result of asiatikosida content of pegagan extract is $0.08 \%$ and efervesen $0.005 \%$ tablet; Test results for vitamin C content of broccoli extract $13.859 \%$ and efevesen tablet $16.995 \%$. The results of the physical quality test of effervescent tablets showed that the three formulas met the specified requirements. Stability test results for 8 weeks showed that the effervesen tablet of formula 3 met the requirements of physical quality during storage.
\end{abstract}

Keywords: Brocoli, Pegagan, Effervescent Tablets, Antidemensia

\section{PENDAhuluan}

Proporsi penduduk lanjut usia (65 tahun ke atas) pada tahun 2025 diperkirakan akan meningkat dari 5,0\% menjadi 8,5\% (BPS, 2012). Proses penuaan secara perlahan-lahan menyebabkan hilangnya kemampuan jaringan untuk memperbaiki diri dan mempertahankan struktur serta fungsi normalnya. Hal tersebut dapat mengakibatkan kelemahan organ, kemunduran fisik dan timbulnya berbagai macam penyakit degeneratif salah satunya adalah demensia (Arisman, 2013. Mahan, 2008). Di Indonesia, jumlah Orang Dengan Demensia (ODD) diperkirakan akan makin meningkat dari 960.000 di tahun 2013, menjadi 1.890.000 di tahun 2030 dan 3.980.000 ODD di tahun 2050 (World Alzheimer's Report, 2009) .

Demensia adalah suatu sindroma penurunan kemampuan intelektual progresif yang menyebabkan deteriorasi kognisi dan fungsional sehingga mengakibatkan gangguan fungsi sosial, pekerjaan dan aktifitas sehari-hari (Smeltzer, 2001). Obat yang berasal dari senyawa kimia seringkali menimbulkan efek samping yang tidak di inginkan sehingga peneliti ingin mengembangkan antidemensia yang berasal dari bahan alam yaitu brokoli dan pegagan yang dikombinasikan karena memiliki khasiat yang sama sehingga memberikan efek yang sinergis dan meningkatkan aktivitas. Efek farmakologi pegagan sebagai suplemen otak diketahui berasal dari kandungan senyawa triterpenoid khususnya asiatic acid dan asiaticoside (Aprilianto, 2010). Selain itu
Royal Pharmaceutical Society (2009) membuktikan bahwa brokoli mengandung senyawa yang mirip dengan obat-obatan penyakit Alzheimer yaitu senyawa sulforafan. Menurut hasil penelitian Profesor Gabriele Nagel dan Profesor Christine von Arnim dari Universitas Ulm, penderita Alzheimer memiliki kadar vitamin $\mathrm{C}$ yang rendah dalam plasma. Berdasarkan penelitian tersebut vitamin $\mathrm{C}$ dapat mencegah terjadinya demensia atau kepikunan (Riviere, 1998).

Pada penelitian sebelumnya telah dibuktikan bahwa kombinasi dosis ekstrak kering brokoli dan pegagan efektif meningkatkan daya ingat pada mencit jantan dengan dosis $0,069 \mathrm{~g} / \mathrm{kg} \mathrm{BB}$ dan sebanding dengan kontrol positif prostigmin $0,1 \mathrm{mg} / \mathrm{kg}$ BB (Nihaya, 2016). Salah satu kendala obat tradisional yang diperoleh dari ekstrak tanaman adalah kelarutannya yang kecil dalam air, sehingga membatasi absorpsi zat aktifnya. Masalah lainnya adalah bau dan rasa dari ekstrak tanaman brokoli dan pegagan yang kurang enak. Salah satu upaya untuk memperbaiki bau dan rasa, yaitu dengan memformulasikan ekstrak tanaman tersebut dalam bentuk sediaan tablet efervesen.

Tablet efervesen mulai banyak diformulasikan karena lebih menarik dibandingkan tablet konvensional. Tablet efervesen dalam penggunaannya akan menimbulkan gelembung gas $\mathrm{CO} 2$ dari reaksi antara asam basa yang bercampur dengan air. Keuntungan yang dimiliki tablet efervesen, selain cara penggunaannya yang menarik, 
tablet tersebut dapat memberi cita rasa menyenangkan dari reaksi karbonasi, tablet mudah digunakan setelah dilarutkan, nyaman, lebih mudah diberikan kepada pasien yang sulit menelan kapsul atau tablet, serta lebih stabil untuk bahan aktif yang tidak stabil dalam air (Siregar, 2010). Tablet efervesen berbeda dengan tablet konvensional, selain pada penggunaannya juga pada komposisi bahan yang digunakan. Komponen utama dalam formula tablet efervesen adalah bagian asam dan bagian basa, dimana bagian tersebut yang akan menghasilkan dan memberikan efek gelembung seperti soda buih jika bercampur dengan air. Sumber asam yang digunakan antara lain asam sitrat dan asam tartrat. Kombinasi asam tersebut dalam tablet efervesen dapat memperbaiki kecepatan alir dan porositas (Anam, 2013). Sumber basa yang digunakan adalah natrium bikarbonat karena dapat mempercepat kelarutan, memberikan rasa tablet yang enak, serta aroma pada sediaan (Murdianto, 2012).

Penelitian ini bertujuan untuk memformulasikan ekstrak brokoli dan pegagan menjadi sediaan tablet efervesen sebagai antidemensia serta untuk menentukan formula terbaik tablet efervesen brokoli dan pegagan berdasarkan variasi perbandingan konsentrasi asam yang berbeda.

\section{METODE PENELITIAN}

\section{A. Alat dan Bahan}

Alat yang digunakan yaitu timbangan analitik $\left(\right.$ And $\left.^{\circledR}\right)$, juicer (Oxone $\left.{ }^{\circledR}\right)$, oven $\left(\right.$ Memmer $\left.^{\circledR}\right)$, ayakan, Flowmeter, Moisture Balance (AND MX 50 ${ }^{\circledR}$ ), tanur $\left(\mathrm{Ney}^{\circledR}\right)$, kurs, Vaccuum dryer $\left(\right.$ Ogawa $\left.^{\circledR}\right)$, pencetak tablet (Erweka AR 400 $\left.{ }^{\circledR}\right)$, hardness tester $\left(\right.$ Erweka $\left.^{\circledR}\right)$, friability tester dan alat gelas.

Bahan yang digunakan dalam formulasi tablet: brokoli, pegagan, asam sitrat (brataco), asam tartrat (brataco), natrium bikarbonat (brataco), PVP
K30, stevia powder (cina), beta siklodekstrin (cina) dan laktosa.

\section{B. Pembuatan Ekstrak Kering Brokoli dan Pegagan}

Brokoli dan pegagan dicuci dengan air mengalir sampai bersih, kemudian ditiriskan, masingmasing di juicer. Sari yang diperoleh disaring kemudian dikeringkan menggunakan vaccuum dryer, sehingga diperoleh ekstrak kering.

\section{Pembuatan Sediaan Tablet Efervesen Ekstrak Brokoli dan Pegagan}

Tablet efervesen brokoli dan pegagan dibuat sebanyak 3 formula dengan bobot 4 gram per tablet. Kandungan zat aktif ekstrak brokoli dan pegagan yang digunakan merupakan dosis yang digunakan pada penelitian sebelumnya (Nihaya, 2016). Formula tablet dapat dilihat pada Tabel 1.

Pembuatan tablet efervesen dimulai dengan pembuatan granul yang dilakukan dengan metode granulasi basah dan dibuat granulasi terpisah antara komponen asam dan komponen basa. Granulasi komponen asam dibuat dengan mencampur asam sitrat, asam tartrat, beta siklodekstrin, dan laktosa. Granulasi komponen basa dibuat dengan mencampur natrium bikarbonat, ekstrak brokoli, ekstrak pegagan, stevia powder, dan laktosa. Masing-masing granul ditambahkan PVP sampai massa dapat dikepal kemudian diayak dengan ayakan mesh 14 dan dikeringkan pada suhu $40^{\circ}-50^{\circ} \mathrm{C}$. Selanjutnya diayak kembali dengan ayakan mesh 30. Granul komponen asam dan komponen basa kemudian dicampur hingga homogen. Dilakukan pengujian granul efervesen yaitu uji kadar air.

Tabel 1. Formulasi tablet efervesen ekstrak brokoli dan pegagan

\begin{tabular}{lccc}
\hline \multicolumn{1}{c}{ Bahan } & & Formula (\%) & \\
& FI & FII & FIII \\
\hline Ekstrak Kering Brokoli dan pegagan & 9,5 & 9,5 & 9,5 \\
(1:1) & & & \\
Asam sitrat & 25,1 & 18,83 & 12,56 \\
Asam tartrat & 12,56 & 18,83 & 25,1 \\
Natrium bikarbonat & 38,20 & 38,20 & 38,20 \\
PVP K30 & 3 & 3 & 3 \\
Stevia powder & 3,5 & 3,5 & 3,5 \\
Beta siklodekstrin & 5 & 5 & 5 \\
Laktosa ad & 100 & 100 & 100 \\
\hline
\end{tabular}




\section{Evaluasi Mutu Tablet Efervesen}

Uji mutu fisik tablet yang dilakukan meliputi uji keseragaman bobot (DirJen POM RI, 1979), uji kekerasan tablet (Banker, 1980), uji kerapuhan tablet (Agoes, 2008), uji waktu larut (Europian Pharmacopoeia, 1997), uji kesukaan dan penetapan kadar.

\section{E. Uji Kesukaan}

Dilakukan terhadap ketiga formula dengan perbedaan perbandingan antara konsentrasi komponen asam. Uji kesukaan dilakukan terhadap parameter warna, aroma, dan rasa terhadap tablet efevesen yang telah dilarutkan. Pengujian dilaukan terhadap 20 panelis dengan usia diatas 17 tahun. Hasil uji kesukaan terbaik dari formula dilakukan uji penetapan kadar dan uji stabilitas.

\section{F. Uji Penetapan Kadar Asiatikosida}

Penetapan kadar asiatikosida dalam tablet efervesen brokoli dan pegagan dilakukan dengan cara membuat larutan uji dan larutan standar. Penetapan kadar asiatikosida dilakukan menggunakan HPLC. Analisis penetapan kadar dilakukan di Laboratorium Pusat Studi Biofarmaka LPPM-Institut Pertanian Bogor.

\section{G. Uji Penetapan Kadar Vitamin C}

Penetapan kadar vitamin $\mathrm{C}$ dalam tablet efervesen brokoli dan pegagan dilakukan dengan cara membuat larutan uji dan larutan pembanding, dengan konsentrasi $50 \mathrm{ppm}$, lalu absorbansi diukur pada panjang gelombang $260 \mathrm{~nm}$.

\section{H. Uji Stabilitas}

Uji stabilitas dilakukan terhadap formula tablet terbaik berdasarkan uji kesukaan. Sebanyak 75 tablet dimasukkan dalam wadah lalu disimpan pada suhu kamar dan suhu sejuk. Kemudian didiamkan selama 2 bulan dan setiap 4 minggu sekali dilakukan pengamatan.

\section{HASIL DAN PEMBAHASAN Tablet Efervesen Ekstrak Brokoli dan Pegagan}

Tablet efervesen dicetak pada ruangan dengan kelembaban relatif $30 \%$ dan suhu $<20^{\circ} \mathrm{C}$. Hasil kadar air granul efervesen formula $1(3,205 \%)$, formula $2(3,296 \%)$ dan formula $3(2,51 \%)$. Hasil tersebut memenuhi persyaratan kadar air granul efervesen yaitu tidak lebih dari $5 \%$ (BPOM, 2014).

Kadar air granul yang tinggi akan menurunkan kecepatan aliran granul sehingga granul sukar mengalir. Kadar air dalam masa tablet efervesen merupakan hal penting karena dapat mempengaruhi terjadinya reaksi kimia dini dari efervesen, yaitu ketika granul dalam kondisi lembab yang berarti memiliki kandungan air yang banyak, komponen asam dan basa akan bereaksi dengan air yang menghasilkan gas CO2 (Siregar, 2010).

\section{Evaluasi Fisik Tablet Efervesen}

Tablet efervesen dicetak pada ruangan kondisi kelembaban relatif $25 \%$ dan suhu $20^{\circ} \mathrm{C}$. Evaluasi fisik tablet efervesen dilakukan untuk mengetahui karateristik mutu tablet efervesen yang dihasilkan. Hasil evaluasi fisik tablet efervesen dapat dilihat pada Tabel 2

Tabel 2. Hasil evaluasi sifat fisik tablet efervesen

\begin{tabular}{ccccc}
\hline Sifat fisik granul & $\begin{array}{c}\text { Formula 1 } \\
(\mathrm{X} \pm \mathrm{SD})\end{array}$ & $\begin{array}{c}\text { Formula 2 } \\
(\mathrm{X} \pm \mathrm{SD})\end{array}$ & $\begin{array}{c}\text { Formula } 3 \\
(\mathrm{X} \pm \mathrm{SD})\end{array}$ & Syarat/literatur \\
\hline Keseragaman bobot $(\mathrm{g})$ & $4,06 \pm 0,02$ & $4,07 \pm 0,01$ & $3,90 \pm 0,08$ & FI Edisi III \\
Kekerasan $(\mathrm{kp})$ & $12,07 \pm 1,01$ & $12,52 \pm 1,22$ & $12,06 \pm 1,21$ & $4-10 \mathrm{kp(Sulaiman,} \mathrm{2007)}$ \\
Kerapuhan $(\%)$ & $0,08 \pm 0,01$ & $0,15 \pm 0,06$ & $0,74 \pm 0,01$ & $\leq 1 \%$ (Fonner et al, 1981 \\
Waktu larut & $2,39 \pm 0,63$ & $3,80 \pm 0,50$ & $2,20 \pm 0,10$ & $\leq 5$ menit (Europian Pharmacopeiea, \\
(menit,detik) & & 1997 ) \\
\hline
\end{tabular}

\section{Keseragaman Bobot Tablet}

Keseragaman bobot tablet merupakan faktor penting yang menentukan keseragaman zat aktif dalam tablet yang berpengaruh terhadap keseragaman efek terapeutik dari tablet tersebut. Hasil pengujian menunjukkan bahwa ketiga formula tablet efervesen memenuhi persyaratan Farmakope Indonesia edisi III yaitu tidak ada 2 tablet yang bobotnya menyimpang dari bobot rata-ratanya $\geq 5 \%$ dan tidak ada 1 tablet pun yang bobotnya menyimpang lebih besar dari $10 \%$.

\section{Uji Kekerasan Tablet}

Uji kekerasan tablet dilakukan untuk mengetahui ketahanan tablet terhadap guncangan mekanik pada saat pembuatan, pengepakkan dan pendistribusian. Pada umumnya tablet yang baik dinyatakan mempunyai kekerasan antara 4-10 kp. Namun hal ini tidak mutlak, kekerasan tablet lebih besar dari $10 \mathrm{kp}$ masih dapat diterima, jika masih memenuhi persyaratan waktu hancur/waktu larut yang dipersyaratkan (Sulaiman, 2007). 


\section{Uji Kerapuhan Tablet}

Uji kerapuhan tablet dilakukan untuk mengukur kekuatan tablet, tablet yang mudah menjadi serbuk, pecah dan tergores pada saat pengemasan, pengiriman dan penyimpanan serta dapat menimbulkan pengotor pada tempat pengangkutan dan pengepakkan akan menimbulkan variasi pada berat dan keseragaman isi tablet sehingga tablet tidak layak untuk dijual. Syarat kerapuhan tablet yaitu $\leq 1 \%$ (Fonner, 1981).

\section{Uji Waktu Larut Tablet Efervesen}

Waktu larut tablet efervesen dari masingmasing formula memiliki waktu yang berbeda, hal ini disebabkan pada saat proses pengolahannya dilakukan secara manual sehingga pencampuran bahan untuk karbonasi (komponen asam dan basa) dan bahan tambahan lainnya yang belum homogen sempurna. Tablet efervesen akan larut ketika dimasukkan ke dalam air, sebab campuran antara asam sitrat, asam tartrat dan natrium bikarbonat akan menghasilkan gas karbondioksida $\mathrm{CO}_{2}$ ketika ditambahkan air. Tablet efervesen yang baik mempunyai waktu larut kurang dari 2 menit (Mohrle, 1980). Europian Pharmacopoiea 1997 waktu hancur dari granul efervesen tidak lebih dari 5 menit.

\section{Uji Statistik Analisis Kesukaan}

Uji kesukaan dilakukan terhadap tablet efervesen yang sudah dilarutkan dalam $200 \mathrm{ml}$ air. Uji kesukaan dilakukan terhadap parameter warna, aroma, rasa terhadap tiga formula minuman tablet efevesen. Pengujian dilakukan oleh 20 panelis dengan usia diatas 17 tahun (range usia 21-22 tahun). Data hasil kuisioner yang diisi oleh panelis diolah dengan program SPSS 17, yang dianalisis secara statistik dengan metode Friedman Test. Hasil uji kesukaan dapat dilihat pada Gambar 1.

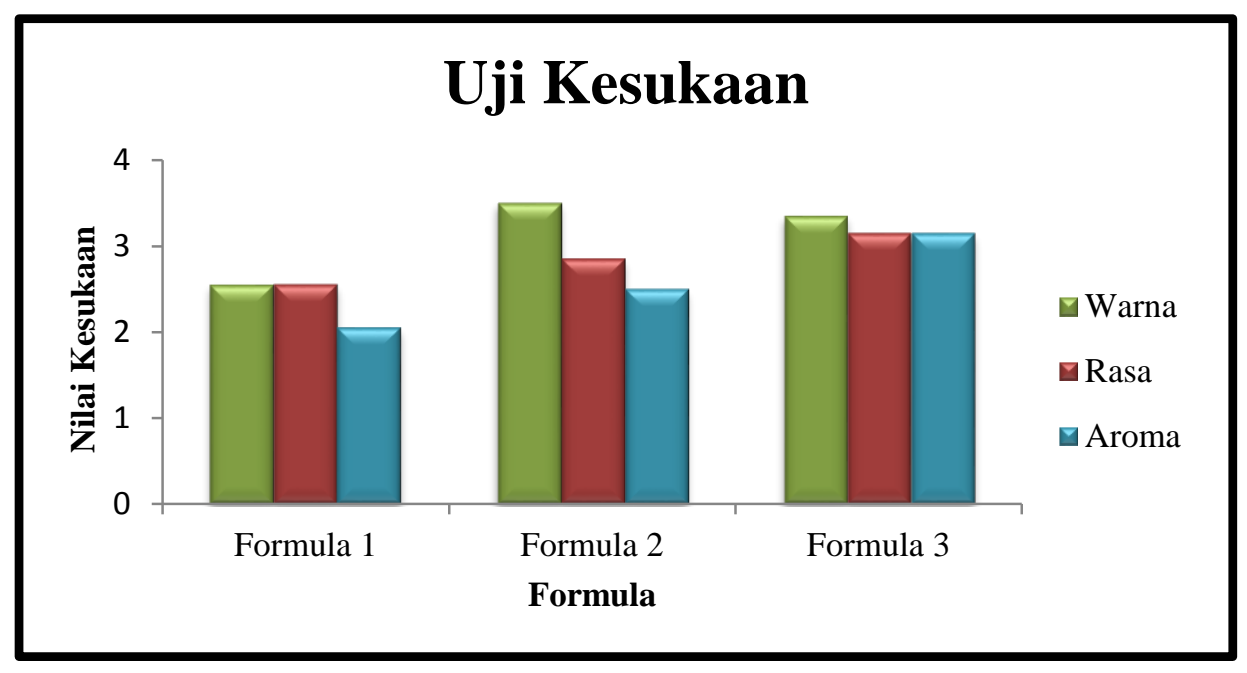

Gambar 1. Grafik uji kesukaan

Parameter warna larutan tablet efervesen mempunyai nilai tertinggi pada formula 3 . Uji statistik parameter warna dengan sig $0,008 \leq 0,05$ artinya seluruh formula berbeda nyata. Hasil uji lanjut LSDrank $\mathrm{F} 1 \neq \mathrm{F} 2=\mathrm{F} 3$.

Parameter rasa larutan tablet efervesen mempunyai range nilai 2,5-3,25 (kurang suka-netral), artinya nilai tersebut masih dibawah nilai suka. Uji statistik parameter rasa dengan sig $0,068 \geq 0,05$ artinya tidak ada perbedaan yang nyata terhadap setiap formula larutan tablet efervesen.

Parameter aroma larutan tablet efervesen mempunyai nilai tertinggi pada formula 3 . Uji statistik parameter aroma dengan sig $0,000 \leq 0,05$ artinya seluruh formula berbeda nyata. Hasil uji lanjut LSDrank F1=F2 FF3.
Konsentrasi penggunaan asam sitrat dan asam tartrat tidak mempengaruhi parameter rasa, tetapi mempengaruhi parameter warna dan aroma.

\section{Kadar Asiatikosida}

Asiatikosida merupakan triterpenoid glikosida yang memiliki aktivitas yaitu untuk merevitalisasi pembuluh darah, meningkatkan perbaikan dan penguatan sel-sel. Asiatikosida juga memiliki aktivitas antioksidan yang cukup kuat (Yonet, 2010).

Penetapan kadar Asiatikosida dilakukan dengan menggunakan kromatografi cair kinerja tinggi atau HPLC. Sampel yang dilakukan pengujian kadar asiatikosida adalah formula terbaik yang disukai oleh panelis yaitu formula 3. Hasil pengujian kadar 
asiatikosida ekstrak pegagan adalah $0,08 \%(0,8 \mathrm{mg} / \mathrm{g})$ dan tablet efervesen $0,005 \%(0,05 \mathrm{mg} / \mathrm{g})$. Hasil analisis kadar asiatikosida dalam ekstrak pegagan tersebut memenuhi persyaratan sesuai literatur yaitu herba pegagan mengandung asiatikosida tidak kurang dari 0,07\% (DepKes, 2008).

\section{Kadar Vitamin C}

Vitamin $\mathrm{C}$ dapat digunakan sebagai nutrisi otak yang dapat mempengaruhi daya ingat. Vitamin $\mathrm{C}$ mengandung antioksidan yang bermanfaat untuk kesehatan. Adanya antioksidan ini dapat melindungi jaringan otak dari kerusakan oksidatif dan inflamasi, selain itu dapat juga membantu tubuh dalam menangkal efek perusakan oleh senyawa radikal bebas dan memperbaiki sel-sel yang rusak sehingga membantu daya ingat agar tetap terjaga dan fokus.

Penetapan kadar vitamin C dilakukan dengan menggunakan spektrofotometer UV-Vis dengan panjang gelombang $260 \mathrm{~nm}$ dengan menggunakan standar vitamin $\mathrm{C}$ sebagai kontrol positif. Pelarut yang digunakan yaitu aqua destilata karena vitamin $\mathrm{C}$ merupakan vitamin yang larut dalam air. Sampel yang digunakan untuk pengujian kadar vitamin $\mathrm{C}$ adalah formula terbaik yang disukai oleh panelis yaitu formula 3. Hasil pengujian untuk kadar vitamin $\mathrm{C}$ yaitu ekstrak brokoli $13,859 \%$ dan tablet efervesen $16,995 \%$ dengan \% kadar dalam tablet $122,62 \%$. Kadar yang berbeda tersebut diduga disebabkan oleh gugus kromofor dalam asam sitrat dan asam tartrat yang terbaca oleh panjang gelombang absorbansi vitamin C. Dalam Farmakope Indonesia Edisi IV tablet vitamin $\mathrm{C}$ mengandung asam askorbat tidak kurang dari 90,0\% dan tidak lebih dari 110,0\%.

\section{Stabilita Sediaan Tablet Efervesen Brokoli dan Pegagan \\ Pengujian ini bertujuan untuk melihat} stabilitas fisik dari sediaan tablet efervesen brokoli dan pegagan pada kondisi suhu yang berbeda. Formula yang diuji stabilita berdasarkan formula yang terbaik pada uji kesukaan yaitu formula 3. Stabilita dilakukan pada suhu yang berbeda yaitu suhu kamar $\left(15^{\circ}-30^{\circ} \mathrm{C}\right)$ dan suhu sejuk $\left(8^{\circ}-15^{\circ} \mathrm{C}\right)$ selama 8 minggu. Hasil evaluasi sifat fisik tablet efervesen stabilita pada suhu kamar dapat dilihat pada Tabel 3 dan Hasil evaluasi sifat fisik tablet efervesen stabilita pada suhu sejuk dapat dilihat pada Tabel 4. Uji penetapan kadar tablet efervesen selama stabilita dapat dilihat pada Tabel 5.

Tabel 3. Hasil evaluasi sifat fisik tablet efervesen stabilita penyimpanan suhu kamar

\begin{tabular}{ccccc} 
Sifat fisik granul & $\begin{array}{c}0 \text { minggu } \\
(\mathrm{X} \pm \mathrm{SD})\end{array}$ & $\begin{array}{c}4 \text { minggu } \\
(\mathrm{X} \pm \mathrm{SD})\end{array}$ & $\begin{array}{c}8 \text { minggu } \\
(\mathrm{X} \pm \mathrm{SD})\end{array}$ & FI Edisi III \\
\hline Keseragaman bobot $(\mathrm{g})$ & $4,06 \pm 0,02$ & $4,07 \pm 0,01$ & $4,07 \pm 0,01$ & Syarat/literatur \\
Kekerasan $(\mathrm{kp})$ & $12,06 \pm 1,21$ & $12,06 \pm 1,30$ & $12,5 \pm 1,27$ & 4-10 kp (Sulaiman, 2007) \\
Kerapuhan (\%) & $0,74 \pm 0,02$ & $0,20 \pm 0,04$ & $0,11 \pm 0,01$ & $\leq$ Fonner et al, 1981 \\
Waktu larut (menit,detik) & $2,20 \pm 0,10$ & $2,16 \pm 0,32$ & $2,48 \pm 0,30$ & $\leq 5$ menit (Europian Pharmacopeiea, 1997) \\
\hline
\end{tabular}

Tabel 4. Hasil evaluasi sifat fisik tablet efervesen stabilita penyimpanan suhu sejuk

\begin{tabular}{ccccc}
\hline Sifat fisik granul & $\begin{array}{c}0 \text { minggu } \\
(\mathrm{X} \pm \mathrm{SD})\end{array}$ & $\begin{array}{c}4 \text { minggu } \\
(\mathrm{X} \pm \mathrm{SD})\end{array}$ & $\begin{array}{c}8 \text { minggu } \\
(\mathrm{X} \pm \mathrm{SD})\end{array}$ & Syarat/literatur \\
\hline Keseragaman bobot $(\mathrm{g})$ & $4,07 \pm 0,01$ & $4,07 \pm 0,01$ & $4,08 \pm 0,01$ & Fdisi III \\
Kekerasan $(\mathrm{kp})$ & $12,12 \pm 1,18$ & $12,23 \pm 0,65$ & $12,23 \pm 0,87$ & $4-10 \mathrm{kp}($ Sulaiman, 2007) \\
Kerapuhan (\%) & $0,74 \pm 0,02$ & $0,21 \pm 0,04$ & $0,13 \pm 0,01$ & $\leq 1 \%$ (Fonner et al, 1981 \\
Waktu larut (menit,detik) & $2,20 \pm 0,20$ & $2,29 \pm 0,15$ & $2,42 \pm 0,10$ & $\leq 5$ menit (Europian Pharmacopeiea, 1997) \\
\hline
\end{tabular}


Tabel 5. Uji penetapan kadar tablet efervesen selama stabilita

\begin{tabular}{lcccc}
\hline Minggu ke- & Jenis & $\begin{array}{c}\text { Kadar } \\
\text { Asiatikosida } \\
(\%)\end{array}$ & $\begin{array}{c}\text { Kadar } \\
\text { Vitamin C } \\
(\%)\end{array}$ & $\begin{array}{c}\% \text { Kadar } \\
\text { vitamin C } \\
(\%)\end{array}$ \\
\hline 0 minggu & Ekstrak & $0,08 \%$ & $13,859 \%$ & - \\
& Tablet Efervesen Formula III & $0,005 \%$ & $16,995 \%$ & $122,62 \%$ \\
\hline \multirow{2}{*}{ minggu } & Tablet Efervesen FIII Suhu Kamar & Tidak terdeteksi & $16,04 \%$ & $115,73 \%$ \\
& Tablet Efervesen FIII Suhu Sejuk & Tidak terdeteksi & $15,65 \%$ & $112,92 \%$ \\
\hline
\end{tabular}

Tablet yang disimpan pada suhu kamar dan suhu sejuk selama 8 minggu menunjukkan masih memenuhi persyaratan keseragaman bobot tablet, kekerasan tablet, kerapuhan tablet, dan waktu larut tablet efervesen sesuai literatur yang telah ditentukan.

Tablet efervesen mengalami penurunan kadar asiatikosida, hal itu diduga karena asiatikosida yang terkandung didalam tablet efervesen terlalu kecil, dari konsentrasi awal yang cukup sedikit yaitu $0,08 \%$, menjadi semakin menurun dan kadarnya tidak dapat terdeteksi oleh alat yang digunakan.

Tablet efervesen mengalami penurunan kadar vitamin C selama waktu penyimpanan 8 minggu. Hal itu diduga karena vitamin $\mathrm{C}$ yang terkandung didalam tablet teroksidasi.

\section{KESIMPULAN}

Brokoli dan pegagan dapat diformulasikan menjadi tablet efervesen. Hasil uji sifat fisik granul dan tablet efervesen menunjukkan bahwa ketiga formula memenuhi persyaratan yang telah ditentukan. Hasil uji kesukaan menunjukkan bahwa tablet efervesen Formula III yang lebih disukai.

\section{UCAPAN TERIMAKASIH}

Terimakasih kepada Direktur Riset dan Pengabdian Masyarakat Ditjen Penguatan Riset dan Pengembangan Kementrian Riset, Teknologi dan Pendidikan Tinggi yang telah mendanai penelitian ini melalui Program Kreativitas Mahasiswa Tahun Anggaran 2017.

\section{DAFTAR PUSTAKA}

Agoes, G. 2008. Pengembangan Sediaan Farmasi. Penerbit Institut Teknologi Bandung. Bandung. 303-315,

Anam, C., Kawiji., Setiawan, R., 2013, Kajian Karakteristik Fisik dan Sensori Serta Aktivitas Antioksidan dari Granul Effervescent Buah Beet Dengan Perbedaan Metode Granulasi dan Kombinasi Sumber Asam, Jurnal Teknosains Pangan, 2 (2), 23020733.
Aprilianto, Angga., Nugroho, Ardi., dan WFR, Iqbal., 2010, Potensi Rumput Pegagan (Centella Asiatica linn) Sebagai Alternatif Suplemen Otak Pengganti Gingkgo biloba, PKM GT, Yogyakarta, Fakultas Farmasi UII.

Arisman, 2010, Buku Ajar Ilmu Gizi: Gizi Dalam Daur Kehidupan, Jakarta, EGC.

Badan Pusat Statistik, 2012, Profil Kesehatan Ibu dan Anak, Jakarta, Badan Pusat Statistik.

Banker, Peck, and Baley, 1980, Pharmaceutical Dosage Form: Tablet, Vol I, Edited by Leon Lachman and Herbert A. Lieberman, Marcel Dekker, Inc., New York, 71.

BPOM. 2014. Peraturan Kepala BPOM RI No.12 tahun 2014 tentang Persyaratan Mutu Obat Tradisional. Jakarta.

British National Formulary 57, 2009, Royal Pharmaceutical Society, Germany, BMJ Group and RPS Publishing.

Council of Europe. 1997. European Pharmacopoeia, Third Edition. Strasbourg. Hlm. 1753.

DepKes. 2008. Farmakope Herbal Indonesia EdisiI Indonesia. Departemen Kesehatan Republik Indonesia. Jakarta.

Direktorat Jenderal Pengawasan Obat dan Makanan RI, 1979, Farmakope Indonesia, Edisi III., Jakarta, Departemen Kesehatan Republik Indonesia.

Fonner, D.E., Anderson, N.R., Banker, C.S., 1981. Granulation and Tablet Characteristic in Lieberman, H.A., Lachman, L., (Eds). Pharmaceutical Dosage Form: Tablet, vol.2, Mercel Dekker Inc., New York, 226-231.

Mahan LK and EscottStump S., 2008, Weight Management, In : Mahan LK, EscottStump S., eds. Krause's Food \& Nutrition Theraphy. 12th ed. St Saunders Elseviers.

Mohrle, R., 1980, Effervescent Tablet in Lieberman, H.A., Lachman, L,.(Eds)., Pharmaceutical Dosage Form : Tablet,1, 164, 1, New York, Marcel Dekker Inc.

Murdianto, W. \& Syahrumsyah, H., 2012, Pengaruh Natrium Bikarbonat Terhadap Kadar 
Vitamin C Total Padatan Terlarut dan Nilai Sensoris dari Sari Buah Nanas Berkarbonasi, Jurnal Teknologi Pertanian, 25.

Nihaya, A., 2016, Kajian Potensi Efek Antidemensia Ekstrak Brokoli dan Pegagan Pada Mencit yang diinduksi Skopolamin, Skripsi, Bogor, Program Studi Farmasi FMIPA UNPAK.

Riviere, S. Birloquez-Aragon, I., Nourhashemi, F., \& Vellas, B. 1998. Low Plasma Vitamin C in Alzheimer Patients Despite an Adequate Diet. International Journal Of Geriatric Psychiatry 13,.749-754.

Siregar, CJP. 2010. Teknologi Farmasi Sediaan Tablet Dasar-Dasar Praktis. ECG. Jakarta.163.

Smeltzer, C. Suzanne dan Bare G. Brenda., 2001, Keperawatan Medikal Bedah, Edisi 8, Jakarta, EGC.

Sulaiman, T. N,. S. 2007. Teknologi dan Formulasi Sediaan Tablet. Pustaka Laboratorium Teknologi Farmasi Fakultas Farmasi UGM. Yogyakarta.

World Alzheimer's Report, 2009, London, Alzheimer's Disease International.

Yonet T I, Dhimas. 2010. Isolasi Asiaticosida dari Herba Pegagan dan Penetapan Kadarnya Menggunakan HPLC. Skripsi. Universitas Muhammadiyah. Surakarta. 